\title{
Stories of Success: African American Speech-Language Pathologists' Academic Resilience
}

Sarah M. Ginsberg

Eastern Michigan University, sginsberg@emich.edu

DOI: doi.org/10.30707/TLCSD2.3Ginsberg

Follow this and additional works at: https://ir.library.illinoisstate.edu/tlcsd

Part of the Other Social and Behavioral Sciences Commons

\section{Recommended Citation}

Ginsberg, Sarah M. (2018) "Stories of Success: African American Speech-Language Pathologists' Academic Resilience," Teaching and Learning in Communication Sciences \& Disorders: Vol. 2: Iss. 3, Article 4.

DOI: doi.org/10.30707/TLCSD2.3Ginsberg

Available at: https://ir.library.illinoisstate.edu/tlcsd/vol2/iss3/4

This Scholarship of Teaching and Learning Research is brought to you for free and open access by ISU ReD: Research and eData. It has been accepted for inclusion in Teaching and Learning in Communication Sciences \& Disorders by an authorized editor of ISU ReD: Research and eData. For more information, please contact ISUReD@ilstu.edu. 


\title{
Stories of Success: African American Speech-Language Pathologists' Academic Resilience
}

\begin{abstract}
Approximately $7.7 \%$ of the membership of the American Speech-Language-Hearing Association identifies itself as being a minority in contrast with $23 \%$ of the United States population (ASHA, 2016; U.S. Census Bureau, 2014). In order to address this gap, undergraduate and graduate preparation programs need to be able to effectively attract, retain, and graduate clinicians that represent greater diversity. The academic resilience framework suggests that by learning about how students who are at-risk for failure were able to succeed, we can learn about how to improve the outcome for similar students. In this qualitative study, 11 African American speech-language pathologists were interviewed to identify barriers and keys to their academic success on route to becoming speech-language pathologists. Experiencing microaggressions during their educations, including being isolated and stereotyped, were commonly described barriers that needed to be managed. Participants identified caring mentors, a strong sense of determination, and the development of communities outside of their academic programs as keys to their academic success.
\end{abstract}

\section{Keywords}

African American, academic resilience, higher education, microaggressions 
Research has indicated that minority students fail to complete undergraduate coursework disproportionally more often han non-minority peers (American Speech-Language-Hearing Association [ASHA], 2015; Saenz, Wyatt \& Reinard, 1998), resulting in a lowered representation of minorities in the profession. As a profession, it is our responsibility to assure that we, academics in communication sciences and disorders (CSD) programs provide equal opportunity for education in our speech-language pathology and audiology programs to all students, independent of race, ethnicity, gender, or sexual orientation. Given the shortage of diverse colleagues in our profession, we can ill afford to lose those minority students who demonstrate that they are academically qualified and clinically talented from programs where they are enrolled to become speechlanguage pathologists (SLPs). To retain strong students who are minorities, it is incumbent on our academic institutions to under+stand how to improve retention and academic success for all students.

At this time, only $7.7 \%$ of the professionals in the fields of speech-language pathology and audiology self-identify as minorities (ASHA, 2016a). Despite the outstanding efforts of the ASHA's Office of Multicultural Affairs and Resources (ASHA, 2017a) which has worked to create programs and resources that address all forms for cultural and linguistic diversity for SLP professionals and those we serve, we have not seen a significant rise in the diversity to even $10 \%$ in almost 20 years of effort at increasing minority representation (Stewart \& Gonzalez, 2002). Previous attempts to improve retention in higher education have often been oriented toward increased understanding of why minority students separated from their academic programs (ASHA, 2015; Crosley, Heagney, \& Thomas, 2009; Green, 2006; Stephens, Hamedani, \& Destin, 2014). Factors previously identified by these studies as causes for student lack of persistence include not being academically prepared for higher education, limited family support, difficulty adjusting to the social and academic environment, understanding how to navigate higher education, and a lack of support from within the institution. While it is important to understand why students separate from their programs, there has been minimal success in increasing diversity of the profession because of focusing on the causes of attrition.

\section{Academic Resilience}

The academic resilience framework seeks to understand "the process and results that are part of the life story of an individual who has been academically successful, despite obstacles that prevent the majority of others with the same background from succeeding" (Morales \& Trotman, 2004, p. 8) rather than looking at why a subgroup of students is unsuccessful in higher education. While it is critical to acknowledge that no under-represented or minority group is homogeneous in nature, giving students and professionals who share commonalities in their backgrounds the opportunity to give voice to how and why they were successful allows educators a chance to gain knowledge and insight into the higher education process from their unique perspectives. In this way, the academic resilience framework acknowledges both the power of student voice, which recognizes the value of students participating in discussions about their own education (Carlile, 2012; Fleming, 2015) and the strategies of students who have been successful in light of obstacles (Morales, 2008a, 2014).

The academic resilience framework considers four factors that may be valuable to examine in understanding students' resilience: risk, vulnerability, protective, and compensatory factors (Kitano \& Lewis, 2005; Morales, 2008b, 2014). The impact of these factors varies, depending on the nature of scenarios the students finds themselves in. Risk factors are issues related to the 
student's background and may put the student at risk for not succeeding, independent of the academic context, including issues such as poverty, abuse, and parental neglect. Vulnerability factors are student characteristics that may pose risks in certain circumstances, but not other. For example, gender and race may pose no challenges in low risk environments, such as family communities, but in higher risk contexts, such as graduate education, might be a significant problem depending on the academic environment. Protective factors might reflect the student's own individual strengths that might lessen the risks they face, such as effective social skills, positive self-esteem, or external factors such as inspiring role models. Compensatory factors are strategies that the student might use to succeed and protect themselves from threat or risk. Examples of compensatory factors include clear academic and career goals or knowing how to effectively self-advocate.

Because just over 3\% of SLPs are African American (ASHA, 2016a), we need to increase our understanding of mechanisms that successfully fostered the academic development of those who are currently practicing in the field. Given the overall lack of significant success that we have previously experienced in increasing the diversity of the profession, this approach varied from previous studies in order to understand the "exceptional academic achievement in the face of adversity" that African American colleagues faced in achieving their goal of becoming SLP professionals.

\section{Research Question}

In an attempt to improve our understanding of retention issues facing minority students in speechlanguage pathology, this study examined mechanisms of success that African American SLPs (AASLPs) used to persist in their academic programs. This initial research was designed to explore the stories of AASLPs in order to identify patterns of supports and mechanisms that were instrumental to their success in the field such that we might be able to replicate these patterns and improve recruitment and retention of African Americans in speech-language pathology in the future.

\section{Method}

This qualitative study used data collected from individual interviews with AASLPs. Participants identified factors that they felt were barriers or obstacles they needed to overcome in their academic preparations and helped them become SLPs. The use of individual interviews affords us the first-person perspective of the participants to provide their understanding of the socially constructed nature of reality of CSD education (Denzin \& Lincoln, 2003).

Participants. Volunteers were recruited in accordance with the approved Institutional Review Board (IRB) plan which solicited participants who were attending an annual National Black Association for Speech-Language and Hearing (NBASLH) Convention through a NBASLH publication and website. Participants were asked to contact the study author if they self-identified as African American SLPs (AASLPs) and were willing to be interviewed. Additional participants were recruited through snowball sampling when participants volunteered to share study information with their colleagues. Eleven SLPs, two men and nine women, who currently hold the Certificate of Clinical Competence (CCC-SLP) from ASHA participated in the study (ASHA, 2016b) participated in this study. Holders of the CCC-SLP have completed a master's degree at a minimum, from an accredited graduate program and have passed the national examination for 
speech-language pathology. The number of years participants held the CCC-SLP ranged from one to 20 years, with an average of 11 years and ranged in age from 26 to 47 years of age. Participants had earned degrees from variety of educational institutions, including degrees from public and private historically black colleges and universities (HBCU), public universities, and private universities. The highest degrees earned included two clinical doctorates, three research doctorates, two in-process research doctoral students, and four master's degrees. Table 1 lists participant demographic data, including educational institution type, degrees held, and current working settings.

Table 1

Participant Demographics

\begin{tabular}{|c|c|c|c|c|c|}
\hline Participant & $\begin{array}{l}\text { Undergraduate } \\
\text { Institution }\end{array}$ & $\begin{array}{l}\text { Graduate } \\
\text { Institution(s) }\end{array}$ & Degree & $\begin{array}{l}\text { Years } \\
\text { Cert. }\end{array}$ & Work Setting \\
\hline Chiron & Public & Public/Public & Ph.D. & 18 & Public University \\
\hline Karen & Public & Public/Public & Ph.D. & 9 & Private University \\
\hline Jeremiah & HBCU public & Public/Public & Ph.D. & 10 & Public University \\
\hline Helen & Private & Public/Private & $\begin{array}{l}\text { Ph.D. } \\
\text { program }\end{array}$ & 20 & Private University \\
\hline Beverly & HBCU public & Public/Public & $\begin{array}{l}\text { Ph.D. } \\
\text { program }\end{array}$ & 12 & Public University \\
\hline Nandi & Private & $\begin{array}{l}\text { HBCU } \\
\text { public/Private }\end{array}$ & CD-SLP & 12 & K-12 Education \\
\hline Katarina & Public & Public/Private & CD-SLP & 12 & Healthcare \\
\hline Kezia & HBCU private & Public & Master's & 8 & Healthcare \\
\hline Rachel & Private & Public & Master's & 12 & Healthcare \\
\hline Michaela & Public & Public & Master's & 1 & Healthcare \\
\hline Joslin & HBCU private & Public & Master's & 10 & K-12 Education \\
\hline
\end{tabular}

Data Collection. All participants were individually interviewed for up to one hour each by the author. All interviews were semi-structured and focused on open-ended questions regarding (a) what obstacles they felt they faced during the academic careers and (b) factors that they felt were key to their academic success. Six participants were interviewed face-to-face and five were interviewed by phone, in compliance with the IRB protocol. The use of interviews allowed for gaining insights into the individual's perceptions and attitudes (Creswell, 2003) and facilitated the participants ability to describe their experiences in rich detail, providing "thick descriptions" (Denzin \& Lincoln, 2003, p. 98).

Data Analysis. Interviews were audio recorded using digital audio-recorders and transcribed by a professional transcriptionist. All participants were given (or selected) pseudonyms to protect their 
identities. No identifying information was shared within the narratives. Creswell's (2003) guidelines for the analysis of the transcriptions through the process of reduction and interpretation were followed. Data was analyzed at the sentence level in the context of the individual's narrative to identify initial codes. Codes from each narrative were then compared to each other before being consolidated into broader categories and themes. These analyses allowed the codes to be refined and organized relative to each other. As codes were analyzed for patterns and themes, they were "linked together" (Denzin \& Lincoln, 2003, p. 279) to begin forming theoretical models. From the overlap of related codes, themes emerge that are supported by the verbatim narratives found within individual transcripts. Peer debriefing was completed as final themes were reviewed with an AASLP colleague who has expertise in multicultural mentoring and higher education for credibility and authenticity (Creswell, 2003).

\section{Results}

While the primary aim of the study was to identify mechanisms that successfully fostered the academic development of AASLPs who currently are practicing in the field, it felt useful to also understand the context of the barriers or challenges that these professionals experienced in their academic careers while developing their strategies for success.

Vulnerability Factors: "Microaggressions." Participants in the study described microaggressions as a difficulty that they faced as African American students in undergraduate and graduate speech-language pathology programs. Microaggressions were experienced by many SLPs in some form during their academic programs and were often associated with isolation and "culture shock." The general exception to this was for those who completed degrees at an HBCU, either private or public. The five participants who had completed one of their degrees at an HBCU noted that they did not perceive barriers to learning while enrolled in programs at HBCUs. Nandi reported that in attending an HBCU she perceived an attitude amongst her faculty that conveyed "you are here to succeed, and we are going to make sure that you do." Kezia described the nature of older students at her HBCU undergraduate program looking out for the younger students, creating a "nice little family environment."

In contrast, SLPs who completed at least one of their degrees at a non-HBCU school that was either a public or a private university recounted experiences of what they often labeled as "microaggressions." They described comments made by various people involved in their speechlanguage pathology education as representing "hidden racism." Many of the SLPs had been told that they should consider other fields with no explanations offered as to why. Helen noted that she had decided to become an SLP at the age of 16. As she began transitioning toward college planning, a guidance counselor asked "Well, are you sure you want to do that? Do you think that is something that you could handle?" She found it discouraging and though she was successful in her undergraduate program, she shared that "it kind of stuck with me in the back of my mind for quite a while after that." Karen noted that she likewise had "had at least two people who said that maybe I should consider something else; maybe I should leave the master's program early-on. That kind of hit my confidence level." One of the comments was from a clinical educator that Karen recalled said

"I'm not even sure how you got into this program, but maybe you should consider leaving." I didn't understand and I didn't know who to tell because it was a really awkward situation for me. And I remember sitting in her office and I started crying. ... I didn't know who I 
could tell. Would you tell someone else? It was kind of one of those one-on-one microaggressions that you don't really know who you tell this too.

When asked about their interpretation of microaggressions, participants generally declined to attribute blame or explicit racism to the person. Michaela started to say "I don't want to say that it was directly related to my race but..." and did not complete her thought. Nandi was also told that she should "choose a different major-go into special education instead" observing that she was the "only minority in the program...I can't tell you why that professor would say that. I can't speak for him."

Isolation. Numerous participants described variations of microaggressions related to social isolation that they experienced while in school. Joslin expressed interest to her peers about joining a study group. She thought that they were going to include her, but then realized that she had not been counted in.

"Oh we forgot to call you from the study group" ... and I hear them talking. It was clear they had met and studied, and they forgot to call me. And I just remember thinking I don't think they forgot. But after a couple of times of that, you start to figure out this is not an accident.

She quickly realized that she was "on my own and there was no one else...I felt alone in the process." Jeremiah indicated that in his Master's degree program he also inquired about study groups, but never received clear answers, though he too "found out later that they had one and I wasn't invited." Rachel also described the "culture shock" of coming to a new institution and having a hard time finding a "study partner because I am there, and I know absolutely no one" while it was clear to her that others in her graduate program knew each other from their undergraduate experiences. She attributed her lack of interest in partying and drinking, along with her focus on studying, to making it particularly difficult for her to find compatible study group colleagues. Rachel indicated that as a new student, she found the best connections to other students were forged when she was assigned group projects which facilitated meeting her peers. While she preferred independent work, Rachel observed that "group projects kind of help you meet the other classmates. [Otherwise] you are never in a group setting to foster relationships with your cohort members."

The sensation of being an outsider was described by various participants as a lack of "collegiality," as not being "embraced" by their fellow students. Jeremiah noted that while people were "nice, everyone was cordial" he didn't feel "accepted" in terms of being able to form strong, lasting relationships with the other students in his program because he "just felt like an outsider." Chiron also observed that while his fellow students were "great," he didn't "enjoy the same level of collegiality I felt like everyone else did." The sense of isolation, combined with not seeing other African Americans in the field, led him to question his choice of major.

At one point, I did say, "Maybe I got into the wrong major because obviously Blacks don't make it in this field because if they did, I would be seeing them. So maybe this is something that is not kind to minorities."

Michaela similarly noted that "the most difficult [obstacle] to me was seeing the limited representation of minorities within the field." Karen formed the view early that speech-language 
pathology is "a predominantly White profession." Nandi shared this perspective, noting that "you end up feeling alone in a program [when] there aren't very many of you." For her, the lack of visibility of African Americans in the field has led her, along with a few of her African American colleagues, to "feel it is a White woman profession...I do feel that there is some hidden racism in the profession."

"Culture shock." Participants described another form of microaggression when they described the "culture shock" of enrolling in their SLP program and being treated as a stereotype rather than as an individual. Many found themselves to be the only African American in their program. These participants noted that they had grown up in communities where there was diversity and that for this reason they had no expectations of experiencing difficulties in a predominantly White institution (PWI). Joslin noted "It is shocking to me because here it is 2003 and 2004...just about everyone was around my age, so 20s, and that was weird. That was my first time dealing with a subtler form of racism" that was evident in the "self-segregation" in her academic program. Kezia, who had grown up in a number of different regions and very large cities, had no expectations of being treated differently because of her race, indicated "it was pretty much the first time I felt like I was actually being treated just a little bit differently because of any preconceived notions they may have had about African Americans." She went on to observe that the realization that people grouped her into a stereotype based on the color of her skin "was really just a shock" and she thought to herself "wait, there is another America here that I really have not been exposed to be before." Joslin also shared that she grew up in a very diverse town.

I didn't think that going to a predominantly White institution at the graduate level would be too different... So the fact that I got to [graduate school] and some of the things that I experienced...that was kind of culture shock for me.

Jeremiah had attended a high school that was all African American and before going to a public HBCU for his undergraduate degree. However, he chose a public PWI university because of his academic interests. He recalled attending his first day of orientation and realizing that he was the only African American in the room was a "shock to my system." In his fellow students, he "sensed some hesitation" and thought that perhaps that they were "maybe just a little intimidated and I wasn't welcome into those circles."

Being treated as a stereotype rather than as an individual was a very specific form of microaggression that many SLPs reported. Helen noted that African American students who experience being viewed through the lens of a stereotype "come in with a feeling of inferiority." One implication of thinking that all African Americans are part of a stereotype, and are the same, is that educators were reported to assume that the sole African American in the classroom represented the entire Black experience. Chiron shared his experience as a student

In those classes when we would talk about African-American dialect... "Can anyone demonstrate the African-American dialect?" And here I am the only Black in the program. They meant well but... and we hear this a lot from students ...having to carry the burden of being the African American experience for all of your classmates.

Kezia felt that she had been treated as a stereotype when a professor, making a joke about marijuana during class, "singled" her out as the person who would know about drugs because "everyone else was Anglo-Saxon and I was the only African American." Kezia further noted that 
even on topics that were not educationally related she experienced being viewed as a stereotype. When she asked a professor at her new university in a new town about a radio station playing in their office, she was initially mystified by the response.

I said "Wow, I really like this radio station. What kind of [classical] composers are on here?" And instead of really internalizing what I had just asked them, they assume I was, whatever stereotype they were associating with and they were just like, "This doesn't play rap or anything." Just little microaggressive patterns like that threw me off. I was very confused at first and it literally took other African Americans, who had experienced that more, to explain it to me what was happening. Because I was just confused.

Joslin also felt that she might be carrying the burden of being the only African American for her entire class when one of her professors spoke about adult neurogenic disorders that were associated with "all the Black diseases that Black people have... and you know being the only Black person in the classroom thinking, "Oh my gosh, is everyone looking at me right now?" She noted that this professor also repeatedly said "Afro Americans" in class. After class, Joslin spoke to the professor privately,

By the way, we don't use that term anymore. It is okay to say Black if you want or you can say African American, but Afro American is not really a term that is used anymore. And I said it very nicely, and she said "okay." And the next class, she said it again and straight looked at me. I already knew what I was dealing with.

The microaggressions, including "culture shock" and stereotyping microaggressions, were significant sources of frustration for the AASLPs interviewed in this study. The culture shock that resulted from these behaviors combined with the inability to feel full inclusion also contributed to the participants' sense of isolation. The result of this behavior on the part of faculty and clinical educators was to cause the students to question if they had made appropriate career choices, have self-doubt, and feel "less than" their peers, as numerous participants phrased it.

Protective Factors: Stories of Success. When asked to identify key strategies and mechanisms that they felt had contributed to their academic success, particularly in consideration of the challenges that they reported, participants described factors of mentorship, personal characteristics, and community. In telling their stories, they shared information about who had mentored them and what the mentoring did for them. They also described their efforts to develop a sense of community outside of the formal academic speech-language pathology program boundaries. Descriptions of their own persistence shared common terminology that painted a picture of determination and intentionality.

Mentoring on a "personal level." Every participant shared that there had been at least one key mentor who guided, encouraged, and supported them during some phase of their academic career. Participants experienced support from mentors who were the same race and who were from a different race. Some of the SLPs noted that there might have been something lacking for them due to the racial mismatch when the mentor was not African American. Chiron noted "even though I had strong faculty members that were there for me, whatever I needed kind of thing... because they weren't Black faculty members they would never understand." For Katarina, one of her key mentors was an African American psychologist who helped her "find like-minded speech pathologists" and encouraged her to believe that she could finish her doctorate. She also noted that 
her mentor from her Master's degree, an African American SLP faculty member, was the person who helped her to see her role as an SLP who could "help my culture... and help others." Beverly recalled being "excited" about having an African American professor.

While some participants spoke specifically of mentors who were African American, most talked about the fact that they had no one who looked like them, but that they still found support because of the mentor's attitudes. Karen reported that she "had mentors along the whole way, of all races, who were able to speak to me and ...help me navigate." For her, what was most important was the messages that she received from her mentors that the "field needs me" and "encouraged" her. Kezia noted that "none of my mentors when I was in the program were necessarily African American, but I didn't care because they cared....I always felt like I had someone to go to or to lean on for assistance." What mattered most to Kezia was that her mentors "took me under their wing."

Though there were mentor characteristics that varied from story to story, it was clear that for most AASLPs, the mentor was not just a person who was there to teach them. A mentor was someone who cared about them on a "professional level, but also on a personal level" as Michaela described it. Many AASLPs also described mentoring that was "personal." For Michaela, the professional aspect of mentoring included encouragement from her mentors "to believe in myself, trust myself" and telling her "know that you are capable." She shared that whenever she went to her mentors to ask questions they were good at "not making me feel as if I was less than." The personal level for her was that they cared about how she was outside of the classroom as well as in it. She noted

There is such a heavy emphasis on the schooling that sometimes you do need somebody to take a step back and say, "How are you doing today? What did you do that was good outside of school?" And being able to also ask that professor the same thing; kind of have a bidirectional conversation with them and feel like they know you matter.

Rachel found a mentor in her undergraduate program who helped her by keeping her "encouraged" all throughout her undergraduate and graduate programs. She also found that through membership in the same church, she felt a personal connection through the "mutual bond of religion". This helped Rachel and her mentor stay in touch over an extended period of time, even when she attended graduate school in another state. Rachel also found her passionate faculty to be "fostering" of her love of the field because their goal was for all students to succeed, and they "took the time to make sure that I understood what was happening, what I needed to do" in clinical scenarios.

Beverly credits her mentor in her Master's program with helping her believe that she was capable of completing a doctorate. The mentoring relationship for many SLPs was one that did not end when they finished an educational program and moved on to their next career stage. Beverly referred to that mentor as someone who is "still my mentor now." Nandi also credited her mentors with getting her to a graduate program. One of her mentors helped her when she found herself with no therapy materials in a new job setting. She described that having a mentor that she could contact even though she had finished school gave her a "level of comfort." Her mentor was "someone who saw something in me and said, 'You are coming here on a full ride.' She definitely was that person who told me I could do this." Michaela's mentors encouraged her to believe that she could be successful, telling her "just wake up and come to class every day. It gets better.... know that you are capable." 
Jeremiah was also encouraged to pursue as much education as he could by his mentor, which paralleled his mother's encouragement. When asked about key factors to successfully becoming an SLP, Jeremiah began by describing a parallel between his upbringing and his mentor's. By way of explaining what his mentors did for him, he noted

I had to do well in school. I had to do your best and go to college. I remember when I was in high school, my mama told me, "Hey you need to start thinking about your master's degree because a bachelor's degree isn't worth as much so you need to think about a master's degree." So I was always that type of person that wouldn't agree with everything, but I would listen. So I had that in my mind.

Like his mother, his first mentor in his undergraduate program told him "you have the ability to get your Ph.D., and you should do it." He didn't agree with his mentor right away, any more than he did with his mother, but he said again "I had it in my mind." Jeremiah credited mentors for helping him move forward in his academic career including completing his doctorate. He shared that he had "been really lucky to have terrific mentors at every step of the way." People who saw "potential" in him, encouraged him to apply for special opportunities and consistently gave him a "message of belief" that "you can do it" without ever making him feel "less than." He concluded that "seeing someone who believes in you, who is willing to help you, is really valuable."

Other community. Likely in order to combat the pervasive sense of isolation that participants experienced, many sought some sense of community outside of their academic programs when they did not find it in amongst their fellow speech-language pathology students. Jeremiah described connecting with a group of men during his undergraduate program who were not speech-language pathology majors, but were all in education-related fields and were also feeling isolated. He described the group of men who formed a pact as undergraduates to support and encourage each other to all complete their doctorates. "We became good friends and we kind of pushed each other. And two of them were like, 'Hey, we all have to get Ph.D.s.' and I thought they were crazy. And we all entered PhD programs." Jeremiah was the first of his group to complete his Ph.D.

Katarina attended the same public university for her undergraduate and graduate programs, which allowed her to hold on to a social connection that supported her over time.

We kind of went through the process together. We all were minorities, not all AfricanAmerican, but minority in the sense of our cultural backgrounds. And there were a couple of us, maybe two other females, and we inspired each other through some of the courses and we just made sure that we did whatever we had to do to finish. So that was support system; that was my nucleus.

For some AASLPs, formal organizations provided them with a sense of supportive community. Joslin found a sense of community during her graduate program by finding a Black Student Caucus organization that included students from all across campus. She shared that participating in group service events and activities created "my sense of community and sanity. 'I can breathe a little bit.' I felt comfort in that setting." Chiron described finding out about NBASLH and receiving funding 
from his academic department to attend an annual convention. He described "my first NBASLH convention was like an adopted child finding their biological family and going to like a family reunion for the first time. For the first time, I felt like I really belonged in this field." Kezia also found "unofficial mentors" at NLBSLH, people who "would answer my questions" and stayed in contact with her, even after she graduated.

Jeremiah also found a sense of community at NBASLH.

I started coming when I was a first-year grad student, coming from a very isolated environment and then to come here, and a lot of other students were going through the same thing and you have all these mentors; people who want to mentor you, want to help you and then I come back, 12 years later and I see some of the same faces there remembering me as a student. They would say, "We always know you, we always knew you could do it. Here is [this] opportunity." You get that mentorship here and that positive energy here to go back to your institutions.... You feel this energy here and you see so many brilliant Black people who are doing great things, whether they are practitioners, researchers...I mean, you have to smart to be a speech language pathologist- to get through the programs and the challenges and learn about the brain and stuff like that. The Black SLPs I know who have been doing it a while and they have gone through the riggers...they are smart people and so I just love that energy. I love that positive Black excellence and I love to be around that.

"Grit." No participant explicitly credited their own personality or personal characteristics as the reason that they were academically successful. However, in recounting their educational endeavors, they often shared stories that suggested they had a strong sense of determination and goal orientation. Karen noted that when she encountered negative faculty, her mother said to her "just do whatever they are asking you to do and just stay focused on the end goal." Karen reflected that "you have to find the grit to get through." Chiron noted that he became particularly motivated by the clients that he was working with in graduate school, saying "it is the drive of what we do that kept me there." Beverly recounted that she felt that part of her success in becoming an SLP was due to "my determination... because I am that kind of person that you can tell me 'no' as long as you want, but I am just going to keep on going until I get it." For Katarina, knowing that there were so few AASLPs and that our field needed more "gave me a little bit more of a push as to why it is so important for me to stick with this." Michaela characterized her efforts to succeed in graduate school by describing herself as "putting myself out there to be involved" in opportunities that became available in her program or across campus. Kezia similarly described herself as being determined, noting "at the end of the day, I wanted to be an SLP and I was very proactive about it." She noted that despite experiencing microaggressions in her education, she "was able to capitalize on those experiences and be prepared to deal with those kind of behaviors...from whoever came [to her] with that preconceived notion" of stereotypes of African Americans.

\section{Discussion}

The stories that the 11 AASLP participants shared regarding the challenges and their mechanisms for success on their journeys toward becoming SLPs were consistent with the academic resiliency framework. Various forms of microaggressions represent a significant vulnerability in the high risk environment of higher education. Microaggressions are "subtle (often unintentional or unconscious) forms of racial discrimination" (Nadal, Wong, Griffin, Davidoff, \& Striken, 2014, p. 
461) and can be verbal or nonverbal in nature. Microaggressions have been categorized into three different types (Nadal et al., 2014; Sue et al., 2007). Microassaults are explicit racially derogatory comments or nonverbal behaviors which are typically conscious and deliberate, such as the use of "Afro American" by Joslin's professor after Joslin had privately tried to explain that this was a term that was no longer used. Microinsults are thought to be less conscious, but nonetheless work to undermine the racial identity of the individual, such as when Karen was told 'I'm not even sure how you got into this program..." Finally, microinvalidations are perhaps the most subtle form of microaggressions as they may lead the recipient to question whether something negative just transpired. Microinvalidations negate or invalidate the thoughts and feelings of the person of color, such as when Kezia's professor responded to her inquiry about the classical radio station by telling her "This doesn't play rap..."

Microaggressions can be just as harmful as "overt" racism. Self-esteem and life satisfaction are directly impacted by microaggressions, resulting in self-doubt, frustration, discouragement, and feelings of isolation (Nadal et al., 2014; Solorzano, Ceja, \& Yosso, 2001; Sue et al., 2007). Most people described the isolation that they experienced as part of not being fully included by peers. Participants experienced that microaggressions caused them to have self-doubts, not being sure if what had transpired had truly been an insult, and self-doubts about their abilities to become SLPs that were hard to shake for several participants. The AASLPs in this study, who were treated as part of a stereotyped group, often experienced a specific type of "stereotype threat" in which they were treated as the representative for an entire race. This has been termed "spokesperson pressure" (Solorzano et al., 2001, p. 69). Kezia, Joslin, and Chiron all commented on the discomfort that comes from being looked at as the spokesperson for all other African Americans.

Given the descriptions of significant emotional hurdles that had to be overcome on an ongoing basis, it should not be surprising that so few African American students complete educational programs to successfully become SLPs. The participants' stories of the microaggressions that they experienced could understandably lead students to question themselves and their choice of major as Chiron did. However, this group of individuals persisted and succeeded in light of the adversity that they described. The factors of caring mentoring, finding other communities, and a sense of grit that helped each of them be successful, provided academic resilience in the form of protective factors and compensatory strategies that proved to be successful in getting them through their education.

For each of the participants in this study, a caring mentor who was available on a "professional level, but also on a personal level" was critical to their success and was usually the first response given when asked about factors that were key to their academic success. The AASLPs described mentors who demonstrated the ability to look beyond stereotypes, and to give them affirmation and encouragement. The AASLPs included descriptors of mentors who developed "rapport," created "safe spaces," and "cared" are consistent with the empathy and caring that we are expected to bring to our clinical experiences and standards as SLPs (ASHA, 2017b). The critical value of mentors who serve the role of someone to validate academic plans has been noted previously, particularly for students who are members of minority groups (Morales, 2010). Being a caring teacher, as described by Cranton (2001) means being "concerned with establishing a warm and friendly atmosphere in the classroom, providing support, encouraging good relationships among students, and making sure the needs and feelings of each individual are considered" (p. 30). It is also compatible with Roger's (1974) view of "whole person" (p. 104) learning, inclusive of 
cognitive and affective learning facilitated by humanistic educators. For the AASLPs in this study, it was clear that the value of the caring mentor who "took me under their wing" was critical in offsetting the negative messages received during their education. The mentors of these AASLPs delivered messages of "affirmation" telling them "you can do it" and "you are capable" while never making them feel "less than." In this manner, these mentors provided whole person support of their students.

For many of the AASLPs, the ability to find a community outside of their academic program was also identified as invaluable to their success. Solorzano and colleagues (2001) refer to these other communities in academic contexts as "counter-spaces" (p. 70) where negative views of students based on race can be challenged and positive collegial relationships can be formed. Participation in campus groups, and leadership experiences, has been shown to improve African American student retention at both PWI and HBCU institutions (Brittian, Sy, \& Stokes, 2009). For Jeremiah, the informal counter-space that he formed with his fellow students was instrumental in pushing him toward the completion of not only the Master's degree, but a doctorate as well. Joslin described the role of a campus Black Student Caucus as one which allowed her to "breathe" and give her "comfort." For a number of AASLPs, NBASLH served the role of a counter-space away from their academic campus as Jeremiah described coming to his first NBASLH convention where he met people who gave him the connections he needed so that he could take the "positive energy [there] to go back to your institution."

The participants" descriptions of their determination, their goal orientation, and their "grit" were not identified by the participants explicitly as a factor that contributed to their success, but it was a characteristic that many shared. As they described themselves in the process of education, their shared strength of character was evident. Nadal and colleagues (2014) note that self-esteem and self-worth can be mediating factors in overcoming difficulties and challenges in life. Self-esteem may have provided a buffering effect or acted as a protective factor against the onslaught of microaggressions and feelings of isolation that characterized the educational process. The determination that Beverly, Chiron, and Karen shared suggests they were clear about their goals and that this focus helped offset some of the negative feelings that they experienced as a result of microaggressions.

Limitations and Critical Reflexivity. The inherent nature of a qualitative study suggests that there will be some limitations on the generalizability of these findings. However, every attempt was made to represent the perspectives of SLPs from a wide cross-section of geographic regions, educational settings, degrees attained, ages, and work settings. Further, it is important to note that "lives are particular, but they also are typical and generalizable" (Denzin \& Lincoln, 2003. p. 229) particularly within limited cultures and settings. SLPs were the sole focus of the study, excluding audiologists. It should be noted that most of the participants of this study were members of NBASLH and many had completed or were pursuing terminal degrees. As noted here, this may further generalizability as the sample is representative of a group of individuals who have elected to be engaged in their profession at what could be a higher degree than the average SLP who neither actively participates in a professional association nor completes a terminal degree.

Extending this work in the future to include audiologists would provide a better understanding of the educational experiences of African Americans across the range of CSD. There are a number of questions that were not specifically included in the interviews here, but if information was gathered, could add to a fuller understanding of the participants' perspectives. For example, the 
participants were not explicitly asked if they were the first generation in their family to attend college. Some participants shared that their parents did or did not hold college degrees in the process of telling their stories; however, this data was not gathered consistently and purposefully from every participant. As first-generation college students are more often minorities and share some of the challenges with college retention that are shared by African American students in speech-language pathology, an investigation that examined this could yield further understanding about the persistence of students (Coffman, 2011). Other background data about the participants, such as the diversity of the communities that they grew up in or the communities that existed in their higher institutions settings beyond their academic programs were also not fully explored.

Future studies need to learn more about students who begin developing an interest in CSD and then do not persist. At this time, we have no data that reflect how many undergraduate students declare a major in speech-language pathology or audiology, but do not complete their degree in the professions. We also do not have data that reflects what percentage of students who begin but do not complete graduate programs in CSD are of members of a minority group. Collection of this data would be valuable to add to our understanding of why our fields continue to lack significant diversity. Finally, this type of study should be extended to look at the educational experiences of other minority groups.

It is not uncommon in qualitative research to explicate the researcher's positionality and take the researcher's critical reflexivity into consideration, particularly in the context of studies of specific cultures, genders, or race (Denzin \& Lincoln, 2003; Sultana, 2007). Like the participants in this study, I too am a SLP making me a participant-observer. However, unlike the participants, I am a White woman, which means that I am the same race and gender as over $90 \%$ of my colleagues in the field. As an ASHA certified SLP, I am expected to have cultural competence (ASHA, 2016c) which means having an "awareness of oneself as a racial/cultural being and of the biases, stereotypes, and assumptions that influence world views" (Sue et al., 2007, p. 271) along with an awareness of the world views of others. However, I feel strongly that while cultural competency is a respectable goal for clinicians I feel that it is a minimum standard. I prefer to target the cultural proficiency level of the competence continuum such that this research is able to "add to the knowledge base of culturally competent practice" (Cross, Bazron, Dennis, \& Isaacs, 1989, p. 17) I am aware of the advantages of being a double majority member and I was aware that this could result in limitations in the stories of their lived experiences that participants were willing to share with me. In listening to the participants, I attempted to replicate the same cultural competence in the research process as I bring to my clinical and educational practices. I attempted to be empathetic, open, and non-judgmental so that I could understand what their experiences meant to them from their perspective. I am grateful to the participants for their willingness to share their personal, honest, and sometimes difficult stories about their educational experiences.

As our profession moves forward, the diversity gap is likely to grow wider and more critical with the anticipated growth of non-White residents of this country (U.S. Census Bureau, 2015). The limited representation of minorities in speech-language pathology suggests have changed relatively little over the past 20 years. Thus, suggesting that a deficit model, which focuses primarily on why minority students do not persist in programs, has been unsuccessful in helping us understand how to improve their success. This study is the first effort to look at the academic resilience of African Americans in speech-language pathology. It is hoped that by recognizing the challenges that they continue to face in higher education and their mechanisms being persistent 
and resilient, we will be able to move forward to improve the rates of success of our African American students and colleagues.

\section{References}

American Speech-Language-Hearing Association. (2015). Minority student recruitment, Retention and career transition practices: A Review of the literature. Retrieved from http://www.asha.org/practice/multicultural/recruit/litreview/

American Speech-Language-Hearing Association. (2016a). Highlights and Trends: ASHA Counts for Year End 2016. Retrieved from http://www.asha.org/uploadedFiles/2016-MemberCounts.pdf

American Speech-Language-Hearing Association. (2016b). General information about ASHA certification.

Retrieved

from http://www.asha.org/Certification/AboutCertificationGenInfo.htm

American Speech-Language-Hearing Association. (2016c). Cultural competence. Retrieved from http://www.asha.org/Practice-Portal/Professional-Issues/Cultural-Competence/

American Speech-Language-Hearing Association. (2017a). Multicultural Affairs and Resources. Retrieved from http://www.asha.org/practice/multicultural/default/

American Speech-Language-Hearing Association. (2017b). 2014 Standards and Implementation Procedures for the Certificate of Clinical Competence in Speech-Language Pathology, Retrieved from http://www.asha.org/certification/2014-speech-language-pathologycertification-standards/\#Standard_IV

Brittian, A. S., Sy, S. R., \& Stokes, J. E., (2009). Mentoring: Implications for African American college students. The Western Journal of Black Studies, 33(2), 87-97.

Carlile, A. (2012). 'Critical bureaucracy' in action: Embedding student voice into school governance. Pedagogy, Culture and Society, 20(3), 393-412. doi: 10.1080/14681366.2012.712053

Coffman, S. (2011). A social constructionist view of issues confronting first-generation college students. New Directions for Teaching and Learning 127, 81-90. doi: 10.1002/tl.459

Cranton, P. (2001). Becoming an authentic teacher in higher education. Malabar, FL: Krieger Publishing.

Creswell, J. N. (2003). Research Design: Qualitative, Quantitative, and Mixed Methods Approaches (2 ed.). Thousand Oaks, CA: Sage.

Cross, T., Bazron, B., Dennis, K., \& Isaacs, M. (1989). Towards a culturally competent system of care, Volume I. Washington, DC: CASSP Technical Assistance Center, Georgetown University Child Development Center, CASSP Technical Assistance Center.

Crosley, G., Heagney, M., \& Thomas, L. (2009). Improving student retention in higher education. Australian Universities' Review, 51(2), 9-18.

Denzin, N. K., \& Lincoln, Y. S. (2003). Collecting and interpreting qualitative materials. Thousand Oaks, CA: Sage.

Fleming, D. (2015). Student voice: An emerging discourse in Irish education policy. International Electronic Journal of Elementary Education, 8(2), 223-242.

Green, D. (2006). Historically underserved students: What we know, what we still need to know. New Directions for Community Colleges, 135(Fall), 21-28. doi: 10.1002/cc

Kitano, M. K., \& Lewis, R. B. (2005). Resilience and coping: Implications for gifted children and youth at risk. Roeper Review, 27(4), 200-205. 
Morales, E. E. (2008a). The resilient mind: The psychology of academic resilience. The Educational Forum, 72(2), 152-167.

Morales, E. E., (2008b). Exceptional female students of color: Academic resilience and gender in higher education. Innovations in Higher Education, 33, 197-213. doi: 10.1007/s10755008-9075-y.

Morales, E. E., (2010). Legitimizing hope: An exploration of effective mentoring for Dominican American male college students. Journal of College Student Retention, 11(3), 385-406.

Morales, E. E., (2014). Learning from success: How original research on academic resilience informs what college faculty can do to increase the retention of low socioeconomic status students. International Journal of Higher Education, 3(3), 92-102.

Morales, E. E., \& Trotman, F. K., (2004). Promoting academic resilience in multicultural America: Factors affecting student success. New York, NY: Peter Lang.

Nadal, K. L., Wong, Y., Griffin, K. E., Davidoff, K., \& Striken, J., (2014). The adverse impact of racial microaggressions on college students' self-esteem. Journal of College Student Development, 55(5), 461-474.

Rogers, C.R. (1974). Can learning encompass both ideas and feelings? Education, 95,2, 103-114.

Saenz, T. I., Wyatt, T. A., \& Reinard, J. C., (1998). Increasing the recruitment and retention of historically underrepresented minority students in higher education: A case study. American Journal of Speech-Language Pathology, 7(3), 39-48.

Solorzano, D., Ceja, M., \& Yosso, T., (2001). Critical race theory, racial microaggressions, and campus racial climate: The experiences of African American college students. The Journal of Negro Education, 69(1/2), 60-73.

Stephens, N. M., Hamedani, M. G., \& Destin, M. (2014). Closing the social-class achievement gap: A difference-education intervention improves first-generation students' academic performance and all students' college transition. Psychological Science, 25(4), 943-953.

Stewart, S. R., \& Gonzalez, L. S., (2002). Serving a diverse population: The role of speechlanguage pathology professional preparation programs. Journal of Allied Health, 31(4), 204-216.

Sue, D. W., Capodilupo, C. M., Torino, G. C., Bucceri, J. M., Holder, A. M. B., Nadal, K. L., \& Esquilin, M. (2007). Racial microaggressions in everyday life: Implications for clinical practice. American Psychologist, 62(4), 271-286.

Sultana, F. (2007). Reflexivity, Positionality, and participatory ethics: Negotiating fieldwork dilemmas in international research. ACME, 6(3), 374-385.

U.S. Census Bureau. (2014b). United States Quickfacts. Retrieved from https://www.census.gov/quickfacts/

U.S. Census Bureau. (2015). Projections of the Size and Composition of the U.S. Population: 2014 to $2060 . \quad$ Retrieved from https://www.census.gov/content/dam/Census/library/publications/2015/demo/p251143.pdf 